\title{
Electricity generation from rice bran in microbial fuel cells
}

\author{
Shu Takahashi ${ }^{1}$, Morio Miyahara ${ }^{1,2}$, Atsushi Kouzuma $^{1}$ and Kazuya Watanabe ${ }^{1 *}$
}

\begin{abstract}
Background: Rice bran is a by-product of the rice milling process and mostly discarded in Japan. Although many studies have shown that microbial fuel cells (MFCs) are able to generate electricity from organic wastes, limited studies have examined MFCs for generating electricity from rice bran.

Findings: Laboratory-scale single-chamber MFCs were inoculated with paddy field soil and supplied with rice bran for examining electricity generation. Power outputs and microbiome compositions were compared between MFCs containing pure water as the liquid phase (MFC-W) and those containing mineral solution (MFC-M). Polarization analyses showed that both MFCs successfully generated electricity with the maximum power densities of 360 and 520 $\mathrm{mW} \mathrm{m}^{-2}$ (based on the projected area of anode) for MFC-W and MFC-M, respectively. Amplicon-sequencing analyses revealed that Trichococcus and Geobacter specifically occurred in anode biofilms in MFC-W and MFC-M, respectively.
\end{abstract}

Conclusions: The results suggest that rice bran is a feasible fuel by itself for generating electricity in MFCs.

Keywords: Rice bran, Exoelectrogen, Pyrosequencing, Lactobacillales, Desulfuromonadales

Rice bran is a by-product of the rice milling process and made of brown outer layers of rice grains. In Japan, approximately 630 million tons of rice crop are produced annually, of which rice bran makes up approximately $10 \%$ (Matsuoka and Tanaka 2013). Currently, approximately $40 \%$ of rice bran is used for oil production and $15 \%$ for cattle feeds and fertilizers, while the remaining is not specifically used and mostly discarded (Matsuoka and Tanaka 2013). In addition, since rice bran is known to be rich in vitamins and minerals (Faria et al. 2012), a small portion has been used for nutritional supplements and cosmetics. Still, a large portion of rice bran is currently discarded in Japan.

Microbial fuel cells (MFCs) are devices that use living microbes as anode catalysts for generating electricity from organic matter and have attracted social attention due to their ability to generate electricity from waste biomass and wastewater (Logan et al. 2006). For instance, MFCs have been examined for electricity generation

\footnotetext{
*Correspondence: kazuyaw@toyaku.ac.jp

1 School of Life Science, Tokyo University of Pharmacy and Life Sciences, Tokyo 192-0392, Japan

Full list of author information is available at the end of the article
}

from waste sludge (Jiang et al. 2009), cattle manure (Inoue et al. 2013), domestic wastewater (Min and Logan 2004), and brewery wastewater (Feng et al. 2008). In addition, several studies have examined the use of rice bran as a component of mixed waste substrates for electricity generation in MFCs (Moqsud et al. 2013; Schievano et al. 2016). However, no study has examined the potential of rice bran as a fuel for electricity generation in MFCs. In the present study, MFCs were operated with rice bran as the sole substrate, and power outputs and microbiome compositions were analyzed. Rice bran was suspended either in pure water or in mineral solution to check if additional nutrients are necessary for electricity generation from rice bran.

The present study used single-chamber MFCs (approximately $15 \mathrm{~mL}$ in capacity) that were equipped with anodes $\left(5 \mathrm{~cm}^{2}\right.$ in the projected area) and cathodes $\left(5 \mathrm{~cm}^{2}\right.$ in the projected area). An anode was made of graphite felt (GF-80-3F, Sohgoh Carbon), and a cathode was an air cathode that had four polytetrafluoroethylene layers on one side and a platinum catalyst layer $(0.2 \mathrm{mg}$ platinum $\mathrm{cm}^{-2}$; TEC10E20TPM, Tanaka Kikinzoku Kogyo) on the other side (Cheng et al. 2006). A filter paper (No. 
1004-240, GE Healthcare) was sandwiched between the anode and the cathode to prevent them from making contact. An MFC was filled with $15 \mathrm{~mL}$ of pure water (MFC-W) or mineral solution (MFC-M), inoculated with $0.3 \mathrm{~g}$ of rice paddy field soil (obtained at Noda, Chiba, Japan) and supplemented with $0.1 \mathrm{~g}$ of rice bran as the sole organic substrate. The mineral solution contained (per liter) $0.14 \mathrm{~g}$ of $\mathrm{KH}_{2} \mathrm{PO}_{4}, 2.5 \mathrm{~g}$ of $\mathrm{NaHCO}_{3}, 0.54 \mathrm{~g}$ of $\mathrm{NH}_{4} \mathrm{Cl}, 0.20 \mathrm{~g}$ of $\mathrm{MgCl}_{2} \cdot 6 \mathrm{H}_{2} \mathrm{O}, 0.15 \mathrm{~g}$ of $\mathrm{CaCl}_{2} \cdot 2 \mathrm{H}_{2} \mathrm{O}$, $1 \mathrm{~mL}$ of a trace element solution, and $2 \mathrm{~mL}$ of a vitamin solution (DSMZ medium 318, Deutsche Sammlung von Mikroorganismen und Zellkulturen $\mathrm{GmbH}$, Germany). This solution has been used in previous studies, in which MFCs successfully generated electric power (Miyahara et al. 2016a, b). We also examined MFC without adding the mineral nutrients described above (MFC-W), since it has been suggested that rice bran is rich in vitamins and minerals (Faria et al. 2012). We though that electricity generation without nutritional additives would be desirable for reducing costs for the treatment of waste rice bran.

After MFC was filled with the electrolyte (pure water or the mineral solution) containing paddy soil and rice bran, it was put in an incubator at $30{ }^{\circ} \mathrm{C}$. The operation was initiated by connecting the anode and the cathode via an external resistor $(10,000 \Omega)$, and a voltage $(E)$ across the resistor was monitored using a data logger (GL800, Graphtec). When the voltage dropped down to below $0.1 \mathrm{~V}$, rice bran $(0.1 \mathrm{~g})$ was added to recover electric output. MFC performances were evaluated by polarization analyses using a potentiostat (HSV-100, Hokuto Denko) as described previously (Watanabe 2008). The maximum power density (the peak in a power curve, $\left.P_{\max }\right)$ was determined based on the projected area of anode $\left(\mathrm{mW} \mathrm{m}^{-2}\right)$. Protein contents in anode biofilms, cathode biofilms, and electrolyte suspensions were determined to assess the amounts of microbes present there as described previously (Shimoyama et al. 2009). Phylogenetic compositions of bacteria in anode biofilms, cathode biofilm, and electrolyte suspension were analyzed by pyrosequencing of PCR-amplified 16S rRNA gene fragments. DNA extraction, PCR amplification, and amplicon purification were conducted as described elsewhere (Miyahara et al. 2013). Amplicons from different samples were mixed at a same concentration $\left(1 \mathrm{ng} \mathrm{\mu l}{ }^{-1}\right.$ each) and subjected to pyrosequencing using a Genome Sequencer FLX system (Miyahara et al. 2013). Phylogenetic analyses were conducted using a DDBJ 16S rRNA database, a blastn program (Altschul et al. 1997), and an RDP classifier (Wang et al. 2007). Nucleotide sequences determined in the present study were deposited into the DDBJ Sequence Read Archive Database (accession number: DRA005155).

MFC-W and MFC-M were operated for approximately 130 days (Fig. 1), and, during the operation, rice bran was added when $E$ dropped down to below $0.1 \mathrm{~V}$ (once every 10-20 days). After an initial acclimatization period (approximately 30 days), the addition of rice bran resulted in immediate increases of $E$ up to over $0.5 \mathrm{~V}$. We conducted the polarization analysis when $E$ was over $0.5 \mathrm{~V}$, and typical polarization and power curves are shown in Fig. 2a. The average values of $P_{\max }$ were compared between MFC-W and MFC-M (Fig. 2b), showing that MFC-M generated significantly higher outputs than MFC-W. However, it is also noteworthy that MFC-W (containing only rice bran) generated the substantial level of output, suggesting that rice bran is a feasible substrate by itself for generating electricity in MFCs. In MFCs, microbes oxidize organic matter and release electrons that are transferred to anodes, resulting in electricity generation (Watanabe 2008). The present study shows that rice bran is a potent organic substrate. In addition, it is likely that minerals and vitamins contained in rice bran stimulated the growth of microbes involved in electricity generation in MFCs.

We were interested in analyzing microbes involved in electricity generation from rice bran. As the initial step, the amounts of microbes in anode biofilms, cathode biofilms, and electrolyte suspensions in MFC-W and MFC-M as assessed by the protein contents were compared (Fig. 3). We found that, in addition to the anodes, substantial amounts of microbes also attached to the

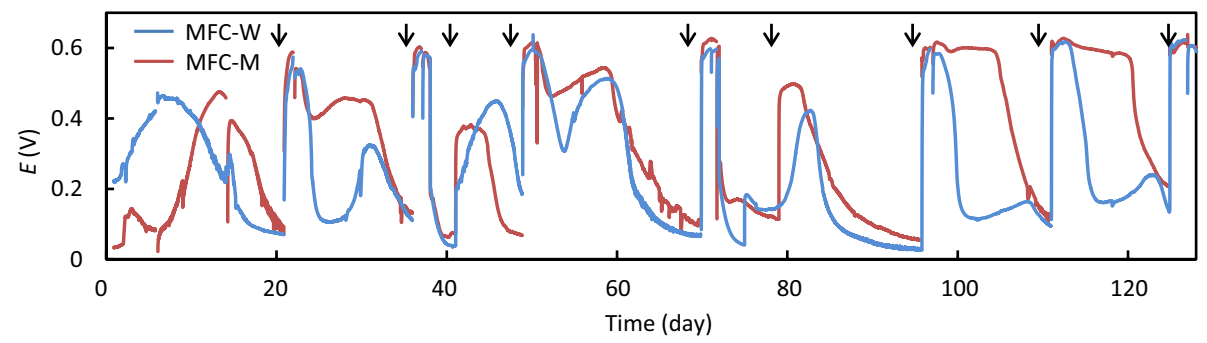

Fig. 1 Changes in Evalues during the operation of MFC-W and MFC-M. Rice bran was added at time points indicated with arrows 

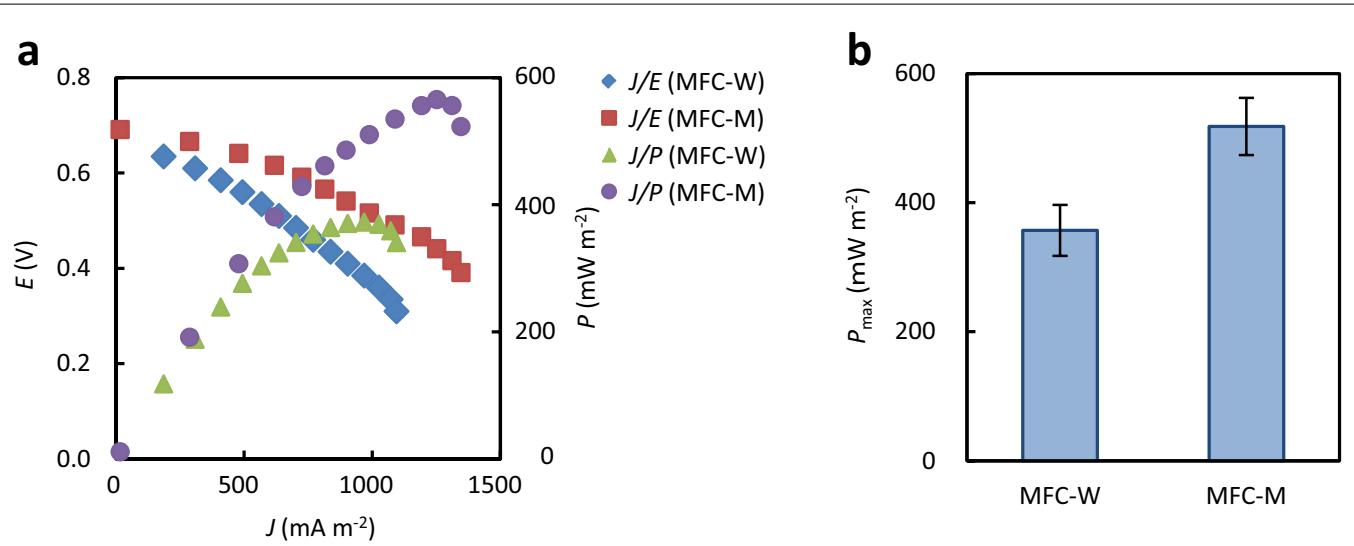

Fig. 2 Evaluation of MFCs fueled by rice bran. a Representative polarization (J/E) and power (J/P) curves for MFC-W and MFC-M. b A comparison of $P_{\max }$ between MFC-W and MFC-M. Datum bars indicate mean values and error bars indicate SD $(n=3)$

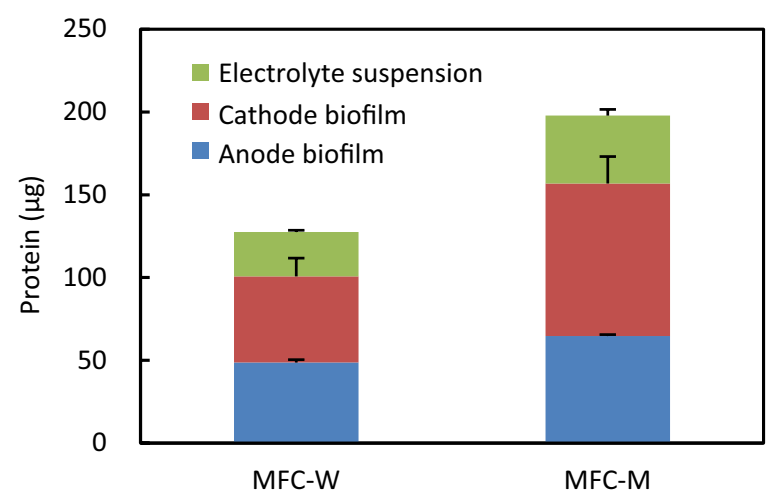

Fig. 3 Protein contents in MFC-W and MFC-M. The total amount of protein in a MFC is the sum of protein contents in anode biofilm, cathode biofilm, and planktonic cells in electrolyte

cathodes. Microbes of the cathodes are considered to respire oxygen that entered from the atmosphere through the air-cathode membranes. In addition, microbes were also present in the electrolyte suspensions, and these may have included fermentative microbes that decomposed rice bran. Comparisons in microbiomes in these habitats were therefore expected to facilitate the identification of microbes responsible for electricity generation at the anodes.

Phylogenetic compositions of bacteria in anode biofilms, cathode biofilms, and electrolyte suspensions in MFC-W and MFC-M were determined by the sequence analyses of amplified 16S rRNA gene fragments (Fig. 4). We focused on bacteria, since all known exoelectrogens (electricity-generating microbes) are affiliated with the Bacteria (Kumar et al. 2015). Figure 4a shows that the orders Bacteroidales and Clostridiales were ubiquitously found in all samples, while some taxa were specifically detected. For instance, the Desulfuromonadales specifically occurred in the anode biofilm in MFC-M, while the Burkholderiales increased in the cathode biofilms in MFC-W and MFC-M. In addition, the Lactobacillales substantially increased in the anode biofilm in MFC-W.

Based on the characteristic distributions and currently available physiological information on members of these orders (Krieg 2011; Wiegel et al. 2006), it is considered that the Bacteroidales and Clostridiales bacteria fermentatively decomposed rice bran in these MFCs. On the other hand, since the family Desulfuromonadales is known to include exoelectrogens, such as those affiliated with the genera Geobacter (Lovley et al. 2011) and Desulfuromonas (Alves et al. 2011), it is reasonable to consider that the Desulfuromonadales bacteria specifically detected in the anode biofilm in MFC-M were responsible for electricity generation. In order to more precisely identify phylogenetic positions of the Desulfuromonadales bacteria detected in MFC-M, major Desulfuromonadales sequences (over $2 \%$ to the total) were used to construct a phylogenetic tree (Fig. 4b). This analysis confirmed that the major members of the Desulfuromonadales are affiliated with the genus Geobacter.

Major Lactobacillales sequences detected in the anode biofilm in the MFC-W were also analyzed (Fig. 4c), and we found that they are affiliated with the genus Trichococcus (Liu et al. 2002). This genus has been described for aerotolerant fermentative organisms that had been isolated from aerobic sludge and anaerobic sediment (Liu et al. 2002). Although no previous studies have identified exoelectrogens that are affiliated with this genus, Trichococcus has been detected in association with the biostimulation of anaerobic digestion with (semi)conductive ferric oxides involving direct interspecies electron transfer 


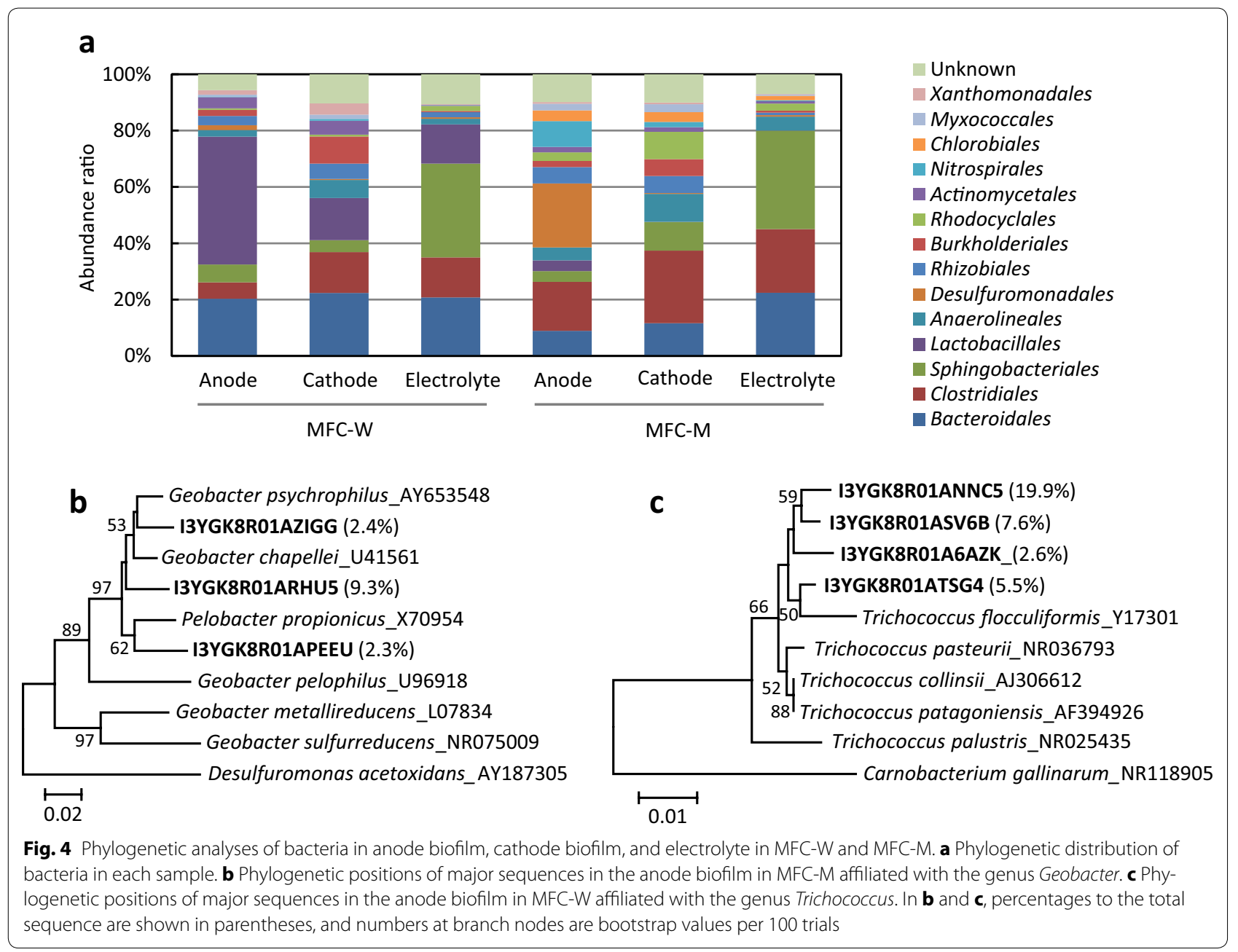

(Baek et al. 2015). Since Trichococcus was highly enriched in the anode biofilm in MFC-W, we suggest that Trichococcus bacteria detected in the anode biofilm are capable of utilizing electrodes as extracellular electron acceptors. It should also be noted that anode microbiomes (including exoelectrogens) changed whether or not the electrolyte was supplemented with the inorganic nutrient components. We deduce that Trichococcus, a genus of lactic acid bacteria, thrives in association with rice bran and adapts to a situation where rice bran is the sole nutrient for growth.

In conclusion, we suggest that rice bran is a feasible fuel for electricity generation in MFCs. Since substantial outputs were generated in MFC-W (rice bran was suspended in pure water), we suggest that rice bran contains sufficient nutrients for electricity generation by microbes. However, it is also shown that the supplementation with the inorganic nutrient solution improves electric output from rice bran. In future studies, the utility of rice bran will be further evaluated in large-scale MFC reactors with different configurations and electrodes.

\section{Authors' contributions}

ST conducted the experiments, MM designed the research, AK analyzed the data, and KW wrote the manuscript. All authors read and approved the final manuscript.

\section{Author details}

${ }^{1}$ School of Life Science, Tokyo University of Pharmacy and Life Sciences, Tokyo 192-0392, Japan. ${ }^{2}$ Meidensha Corporation, Shinagawa, Tokyo 141-8616, Japan.

\section{Acknowledgements}

We thank Nanako Amano for technical assistance.

\section{Competing interests}

The authors declare that they have no competing interests.

\section{Funding}

This work was supported by JSPS KAKENHI grant number $15 \mathrm{H} 01753$.

Received: 12 October 2016 Accepted: 18 November 2016

Published online: 23 November 2016 


\section{References}

Altschul SF, Madden TL, Schaffer AA, Zhang J, Zhang Z, Miller W, Lipman DJ (1997) Gapped BLAST and PSI-BLAST: a new generation of protein database search programs. Nucleic Acids Res 25:3389-3402

Alves AS, Paquete CM, Fonseca BM, Louro RO (2011) Exploration of the 'cytochrome' of Desulfuromonas acetoxidans, a marine bacterium capable of powering microbial fuel cells. Metallomics 3:349-353

Baek G, Kim J, Cho K, Bae H, Lee C (2015) The biostimulation of anaerobic digestion with (semi) conductive ferric oxides: their potential for enhanced biomethanation. Appl Microbiol Biotechnol 99:10355-10366

Cheng S, Liu H, Logan BE (2006) Increased performance of single-chamber microbial fuel cells using an improved cathode structure. Electrochem Commun 8:489-494

Faria SASC, Bassinello PZ, Penteado MVC (2012) Nutritional composition of rice bran submitted to different stabilization procedures. Braz J Pharm Sci 48:651-657

Feng $Y$, Wang $X$, Logan BE, Lee $H$ (2008) Brewery wastewater treatment using air-cathode microbial fuel cells. Appl Microbiol Biotechnol 78:873-880

Inoue K, Ito T, Kawano Y, Iguchi A, Miyahara M, Suzuki Y, Watanabe K (2013) Electricity generation from cattle manure slurry by cassette-electrode microbial fuel cells. J Biosci Bioeng 116:610-615

Jiang J, Zhao Q, Zhang J, Zhang G, Lee DJ (2009) Electricity generation from biotreatment of sewage sludge with microbial fuel cell. Bioresour Technol 100:5808-5812

Krieg NR (2011) Order I. Bacteroidales ord. nov. In: Krieg NR, Staley JT, Brown DR, Hedlund BP, Paster BJ, Ward NL, Ludwig W, Whitman WB (eds) Bergey's Manual of Systematic Bacteriology, vol 4, 2nd edn. Springer-Verlag, New York, p 25

Kumar R, Singh L, Wahid ZA, Din MFM (2015) Exoelectrogens in microbial fuel cells toward bioelectricity generation: a review. Int J Energy Res 39:1048-1067

Liu JR, Tanner RS, Schumann P, Weiss N, McKenzie CA, Janssen PH, Seviour EM, Lawson PA, Allen TD, Seviour RJ (2002) Emended description of the genus Trichococcus, description of Trichococcus collinsii sp. nov., and reclassification of Lactosphaera pasteurii as Trichococcus pasteurii comb. nov. and of Ruminococcus palustris as Trichococcus palustris comb. nov. in the low-G + C gram-positive bacteria. Int J Syst Evol Microbiol 52:1113-1126

Logan BE, Hamelers B, Rozendal R, Schröder U, Keller J, Freguia S, Aelterman P, Verstraete W, Rabaey K (2006) Microbial fuel cells: methodology and technology. Environ Sci Technol 40:5181-5192
Lovley DR, Ueki T, Zhang T, Malvankar NS, Shrestha PM, Flanagan KA, Aklujkar M, Butler JE, Giloteaux L, Rotaru AE, Holmes DE, Franks AE, Orellana R, Risso C, Nevin KP (2011) Geobacter: the microbe electric's physiology, ecology, and practical applications. Adv Microb Physiol 59:1-100

Matsuoka H, Tanaka S (2013) Enhancement antioxidant effect of the fermented rice bran and isolation of the antioxidative component. Mukaizaidan Rep. 102402:1-4

Min B, Logan BE (2004) Continuous electricity generation from domestic wastewater and organic substrates in a flat plate microbial fuel cell. Environ Sci Technol 38:5809-5814

Miyahara M, Hashimoto K, Watanabe K (2013) Use of cassette-electrode microbial fuel cell for wastewater treatment. J Biosci Bioeng 115:176-181

Miyahara M, Kouzuma A, Watanabe K (2016a) Sodium chloride concentration determines exoelectrogens in anode biofilms occurring from mangrovegrown brackish sediment. Bioresour Technol 218:674-679

Miyahara M, Sakamoto A, Kouzuma A, Watanabe K (2016b) Poly iron sulfate flocculant as an effective additive for improving the performance of microbial fuel cells. Bioresour Technol 221:331-335

Moqsud MA, Omine K, Yasufuku N, Hyodo M, Nakata Y (2013) Microbial fuel cell (MFC) for bioelectricity generation from organic wastes. Waste Manag 33:2465-2469

Schievano A, Sciarria TP, Gao YC, Scaglia B, Salati S, Zanardo M, Quiaob W, Dongb R, Adani F (2016) Dark fermentation, anaerobic digestion and microbial fuel cells: an integrated system to valorize swine manure and rice bran. Waste Manag 56:519-529

Shimoyama T, Yamazawa A, Ueno Y, Watanabe K (2009) Phylogenetic analyses of bacterial communities developed in a cassette-electrode microbial fuel cell. Microbes Environ 24:188-192

Wang Q, Garrity GM, Tiedje JM, Cole JR (2007) Naive bayesian classifier for rapid assignment of rRNA sequences into the new bacterial taxonomy. Appl Environ Microbiol 73:5261-5267

Watanabe K (2008) Recent developments in microbial fuel cell technologies for sustainable bioenergy. J Biosci Bioeng 106:528-536

Wiegel J, Tanner R, Rainey FA (2006) An introduction to the family Clostridiaceae. In: Dworkin MM, Falkow S, Rosenberg E, Schleifer KH, Stackebrandt E (eds) The prokaryotes. Springer, New York, pp 654-678

\section{Submit your manuscript to a SpringerOpen ${ }^{\circ}$ journal and benefit from:}

- Convenient online submission

- Rigorous peer review

- Immediate publication on acceptance

- Open access: articles freely available online

- High visibility within the field

- Retaining the copyright to your article

Submit your next manuscript at $\boldsymbol{\nabla}$ springeropen.com 